\title{
Condition Monitoring Uncertainties and Thermal - Radiation Multistress Accelerated Aging Tests for Nuclear Power Plant Cables: A Review
}

\author{
Ehtasham Mustafa1*, Ramy S. A. Afia ${ }^{1,2}$, Zoltán Ádám Tamus¹ \\ ${ }^{1}$ Department of Electric Power Engineering, Faculty of Electrical Engineering and Informatics, Budapest University of \\ Engineering and Economics, H-1521 Budapest, P.O.B. 91, Hungary \\ 2 Department of Electric Power and Machines Engineering, Faculty of Engineering, Helwan University, 1 Sherif Street, \\ 11792 Helwan, Cairo, Egypt \\ * Corresponding author, e-mail: mustafa.ehtasham@vet.bme.hu
}

Received: 18 March 2019, Accepted: 24 June 2019, Published online: 23 September 2019

\begin{abstract}
The low voltage cables in the nuclear power plant have the same importance as veins have in the human body. Since, the cables inside the containment are under a number of environmental stress, out which the thermal and radiation stresses are important and become more effective with the presence of oxygen. These stresses cause the degradation of the insulation and hence may lead to insulation failure. To study the behavior of the cables under the nuclear power plant environmental stress, the cables are subjected to accelerated aging tests in laboratories which helps in determining their withstand capacity and degradation behavior in the harsh thermal-radiation environment. In this paper, the accelerated aging tests conditions are discussed with the focus on the role of certain uncertainty factors which effect the aging markers during the condition monitoring of the insulation material of cable after the accelerated aging tests. This review has been put into a framework to better understand the aging process in the low voltage nuclear power plant cables. In the conclusion part, some future directions in the field of the thermal-radiation multi-stress accelerated aging tests and condition monitoring techniques are also identified.
\end{abstract}

Keywords

aging markers, condition monitoring, low voltage cables, multi-stress aging, nuclear power plant, radiation aging, thermal aging

\section{Introduction}

The aging of electrical insulations has been renowned for many years as a key source of early failure of a wide variety of power plants. Consequently, it is a topic that has received significant consideration. To understand the process of aging and the degradation, a lot of effort has been expended in an attempt to understand the phenomena, such as the types of test and short term accelerated tests to be undertaken to predict the condition of the insulation [1-4]. Prior to the arrival of nuclear technology, the primary factors for the aging of insulation were that of electrical, mechanical, thermal, and medium/environmental stress, Fig. 1. The electrical, mechanical and thermal being the dominant one of these stresses. But as the nuclear technology widely spread, the effects of the environmental stress upon the aging of the insulation had to be given due consideration in addition to the other types of stresses. In the Nuclear Power Plant (NPP) environment, the temperature, radiation and oxygen stressors are the ones which occur in normal everyday operation. While the rest of the environmental stresses are not stimulated during normal

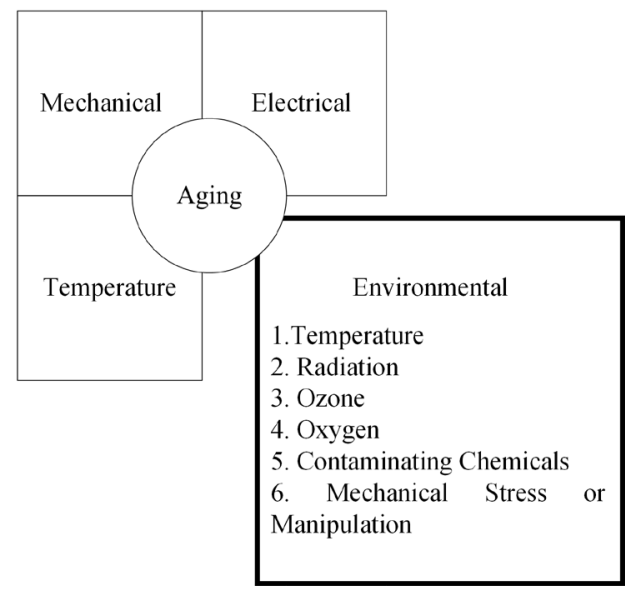

Fig. 1 Aging and types of stresses 
operation. Since, aging is a multif-factor phenomeon, the temperature and oxygen in addition to radiation play a vitol role in the degradation of the insulating materials. As with the presence of radiation, structural changes happen in all those materials which are exposed to it resulting in change in properties, hence radiation adds a particular dimension to the problem of aging [5].

The possible cause of the temperature and radiation stresses in NPP is shown Fig. 2. As shown in the figure, the thermal stress can be due to number of causes. The Ohmic heating and ambient room temperature are the common causes of thermal stress. While the hotspot, which occur at certain points such as cable teminations, and radiation heating have a very low effect [6]. Also the radiation stress can be of low dose gamma $(\gamma)$ irradiation, occurring during normal operation of NPP and high dose gamma $(\gamma)$ and beta $(\beta)$ irradiations, which occur due to accidents.

Since the Low Voltage (LV) cables in NPP have high importance as they not only provide power to the equipments but are also used to control many electrical machines and circuits, so under the multistress environment of NPP it is important to monitor the performance of cables. At present, there is not a single monitoring method that can be applied to acquire data for predicting the long term aging performance of the cable insulation material. Even though a substantial amount of research effort having been devoted to studying the aging of cable insulation material [7-16]. It has also been a challenge for the researchers to determine the key indicators of cable aging that correlate with measurable changes in the insulation material properties, as different materials have a different composition, geometry and pass through different design and fabrication procedures.

To study the effect of aging on the insulation material, accelerated aging tests are carried out in the laboratories. Keeping in view the importance of accelerated aging tests regarding multistress (radiation and thermal) aging in the cables used in NPP, the aim of this work is to find how

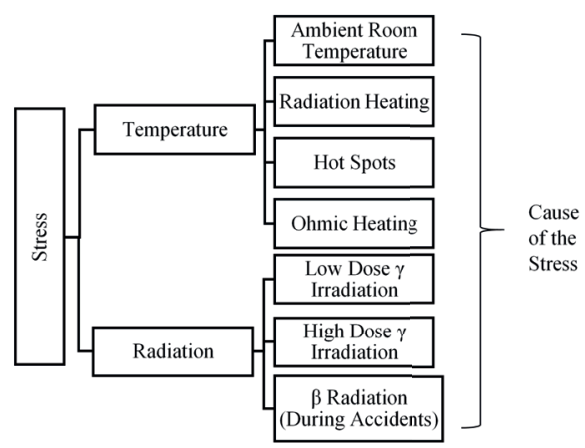

Fig. 2 Cause of temperature and radiation stresses a combination of radiation and thermal stress, effect of environment and inverse temperature can affect the insulation materials of cables, especially LV cables, which have been reported by different researchers. In addition to the causes which have been purposed for such changes by them have also been discussed. The focus has been placed on the determination of changes in the key aging markers (mechanical and electrical properties of insulation materials) during radiation-thermal multi-stress aging conditions.

The paper has been organized as first the thermal and radiation effects in the insulation material are discussed followed by the contribution of dose rate and thermal stress to the radiation stress during accelerated aging tests has been reviewed. In next section, the role of uncertainties such as the sequence of stress, the presence of oxygen and antioxidants and inverse temperature stress on the aging markers of the insulation material during accelerated tests have been discussed with the correlation between the aging markers followed the section. At the end of the paper, a conclusion is drawn by having a debate on the suggestions for the possible future work in the field of the thermal-radiation multi-stress accelerated aging tests.

\section{Thermal-radiation stress effect in insulation materials}

The radiation in NPP can be of four types: alpha $(\alpha)$, beta $(\beta)$, gamma $(\gamma)$ and neutron. The $\alpha$-radiation particles have a short range in the environment due to large mass and hence are attenuated within first few mils of the material. The $\beta$-radiation as mentioned earlier are produced during the accident but their penetration into the material is more and is dependent on the absorbing material. The neutrons vary in mass and penetration capability. Those neutrons having high energy will penetrate into the materials. But due to the presence of neutron reflectors, moderators and radial shielding installed around the reactor core and vessel ensures that the neutrons do not escape the vessel shielding. Hence, no cable within primary containment is exposed to significant neutron dose, with the exception of any cables located inside the neutron shielding or directly adjacent to the reactor vessel. For these cables, they contain inorganic or metallic materials with a high damage threshold for neutron radiation [6].

The $\gamma$-radiations are electromagnetic in nature and have high penetration strength as compared to other radiation types. The dose rate of $\gamma$-radiations is dependent on the reactor power level and varies with its frequency and wavelength. Those $\gamma$-radiations having high frequency will have high energies. Since the cables are located in multiple 
places in the nuclear reactor plant, so they are exposed to $\gamma$-radiations and hence are considered as the primary cause of radiation stress as compared to other radiation types.

Since the insulation materials used in the cables are polymeric in nature, the effect of thermal and radiation stress produce a physio-chemical change in at least one of the properties of the material, as a result, the polymer is degraded and hence the service performance of the material. Many researchers have widely studied the degradation of insulation materials for cable insulation [17-19]. EthyleneVinyl Acetate (EVA), Ethylene Propylene Rubber (EPR), Ethylene Propylene Diene Monomer (EPDM), Low Density Polyethylene (LDPE), Cross-Linked Polyethylene (XLPE), Silicon Rubber (SiR) and Poly Vinyl Chloride (PVC) are some of the relevant polymeric materials used as insulation in the NPP cables among others [20]. There are two types of degradation in the polymer: chemical and physical. The structural change, disruption of old bonds and formation of new ones, in the polymer results in the chemical degradation, while the diffusion of water or plasticizer, low molecular weight components results in physical degradation [21-24]. In order to study the aging of insulation material, it is important to study the effect of the thermal and radiation stress on the chemical structure and reactions inside the material. Fig. 3 shows a simplified schematic of the polymer molecule. The polymer may contain some side branches as shown in the Fig. 3, in addition to backbone of chain of atoms. The polymer molecule is initially ionized due to nuclear radiation, which then combines with an electron and becomes an excited molecule. This excitation

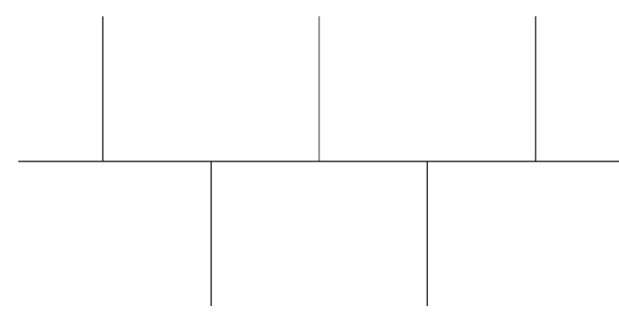

Fig. 3 Simplified structure of polymer molecule

results in breakage of covalent bonds, resulting in following chemical changes in the material $[5,18,19]$ :

Cross-linking, two adjacent macromolecules are covalently bonded. The increase in the cross-linking density results in the increase of the material stiffness. If the process is prolonged, embrittlement of the material is observed.

Chain scission, in which the breakage of one molecular chain two shorter chains is created.

Oxidation, if the material is in the oxygen environment, radiation-induced oxidation is observed. The temperature effect, thermal excitation, helps in this type of degradation. This results in quasi-homogeneous oxidation throughout the bulk of the material [5]. Without the radiation or other means of producing free radicals, at ambient temperature, the rate of oxidation is small [5]. The chemical reactions can occur at the same time, while one of them may be dominant. Table 1 shows the structural change in the polymer molecule as well as the effects due to the chemical reactions on the physical properties of the material while Fig. 4 shows the cyclic process of chemical reaction due to the radiation effect [25], where the process has started due to thermal-radiation initiation by the creation of polymer radical.

Table 1 Structural changes due to the chemical reactions and their effect

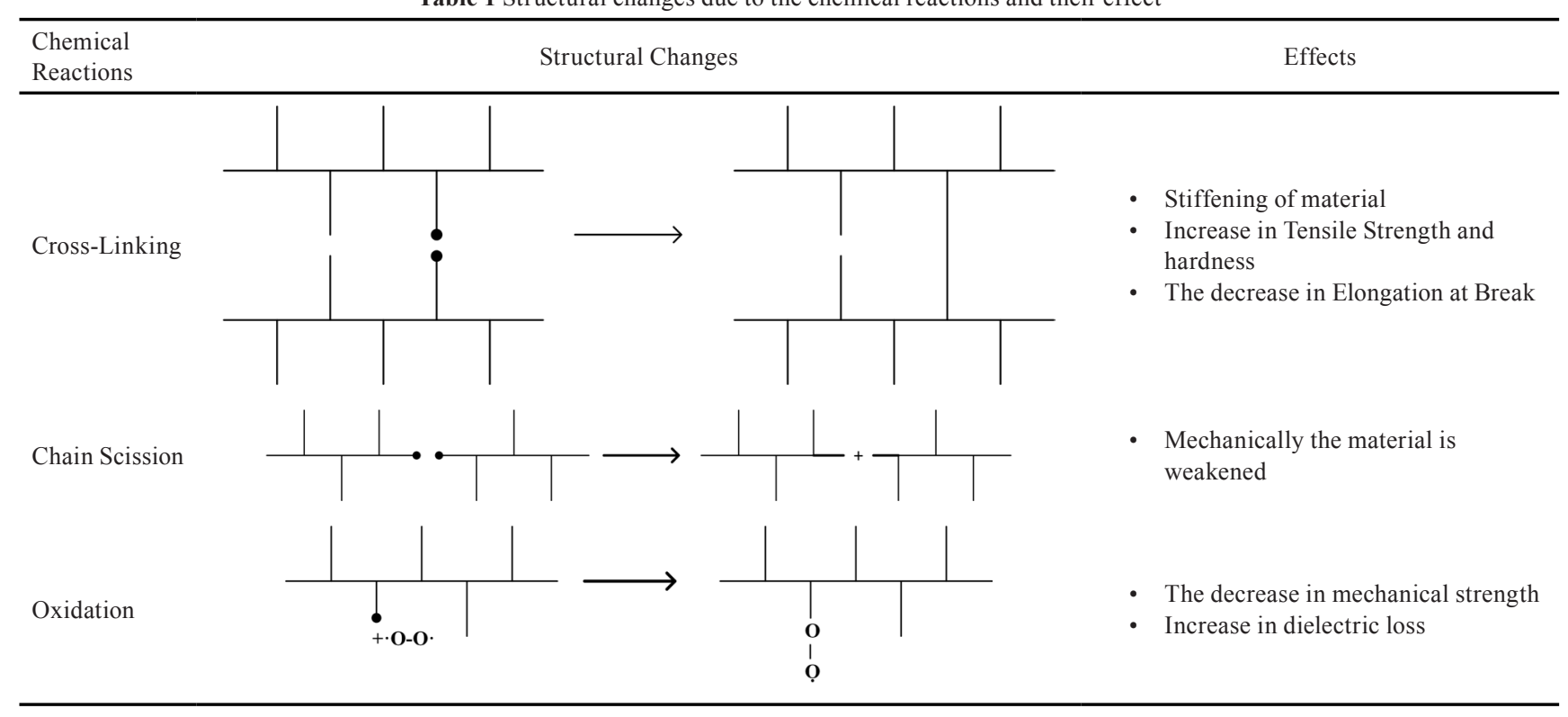




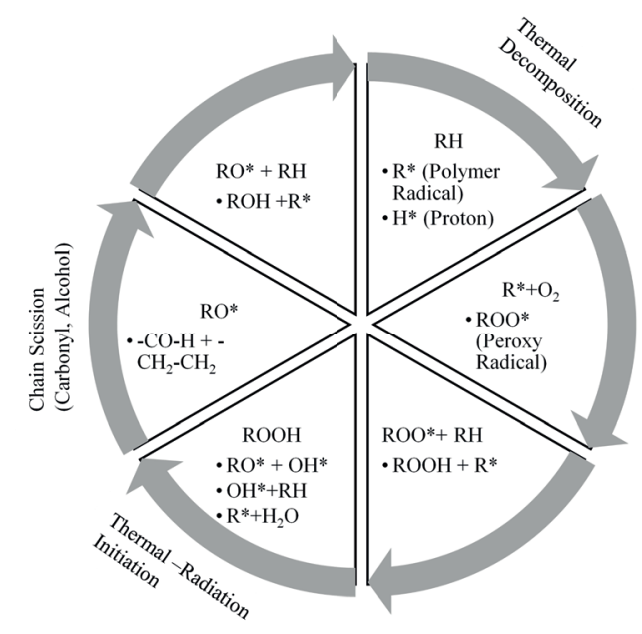

Fig. 4 Cyclic process of chemical reactions due to thermal-radiation stress

This radical can react in any of the chemical reactions discussed above, while in some cases production of gas may also occur. The process can not only occur during radiation but also during post-irradiation with the oxidation [5].

\section{Thermal-radiation multistress accelerated aging tests}

The importance of the study of the degradation of the NPP cables arose from the investigations of the failure of polyvinyl chloride (PVC) and low-density polyethylene (LDPE) cables at the nuclear reactor of the Savannah Nuclear Power Plant [26]. Since then a lot of research has been carried on the aging of the NPP cables, in which single and synergistic effects of temperature and radiation have been studied. The researchers have faced the challenge of simulating the environmental and operational conditions of LV cables located inside and outside the containment of NPP and predicting the degradation processes caused by the radiation and thermal stresses. The challenge is even more difficult considering that each cable manufacturer uses proprietary formulations, including many additives (antioxidants, flame retardants, dyes, fillers, curing agents, plasticizers and other chemicals for thermal and radiation stability) to the base of the polymer, which strongly affect the aging characteristics of insulation compounds.

Furthermore, geometry and design of the cables, as well as the fabrication procedures, can affect the overall aging characteristics. Since the accelerated tests are conducted for the thermal-radiation multi-stress aging, so it is very important to understand how the dose rate and temperature stresses behave in common but not in the universal situation.

\subsection{Dose rate effect}

During the accelerated aging tests the effect of the dose rate on the physical and chemical properties of a certain material is very much dependent on the test environmental conditions; vacuum/ inert gas environment and air / oxygen environment (Line I and Line II in Fig. 5) apart from their molecular structure and formulation. The Fig. 5 shows the dose equivalent damage (DED) for a specific property, for example, elongation at break $(\mathrm{EaB})$ plotted against the dose rate for different environmental conditions at a constant temperature and radiation [27]. According to the figure:

In a Vacuum or Inert gas environment, the dose rate has no effect on the insulation material until the rate of energy absorbed is less than or equal to the rate of dissipation. But if the rate of energy absorbed becomes greater than the rate of dissipation then there will be an increase of temperature within the material and will result in the chemical reactions and increase the physical mechanisms such as diffusion.

In Air or oxygen environment, for certain materials, the low dose rate degrades the insulation materials while for some materials high dose rate effects. In a case the dose rate is adequately high such that in the material because of the oxidation reactions, the dissolved oxygen is used up at the faster rate than it can be replenished from the air surrounding because of diffusion, the equilibrium value of the steady-state oxygen concentration between the material surface and interior will be disturbed. As a result heterogeneity in the oxidation across the insulation material results. While at a lower dose rate, oxidation proceeds further into the sample as the time for oxygen to

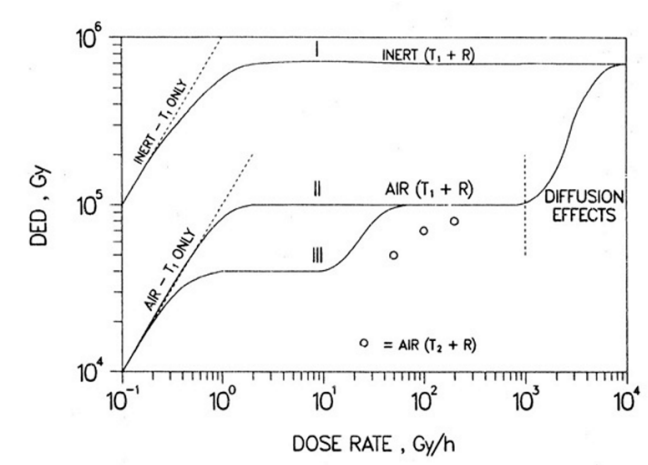

Fig. 5 Dose equivalent damage plotted against dose rate at different environmental conditions [27] 
diffuse is more in this case. Hence insulation materials become more oxidized at lower dose rates [28].

\subsection{Temperature effect}

The contribution of temperature stress during the irradiation period adds more to the degradation of the insulation material, as the radiation-induced chemical reaction would be changed as the temperature changes [29]. In the Fig. 5 the three circles show the change of temperature, $T 2(T 2>T 1)$ with the dose rate at 50, 100 and $200 \mathrm{~Gy} / \mathrm{h} \mathrm{[27]}$. As mentioned earlier, there is a synergistic effect between thermal aging and radiation, which is shown in by the shift of asymptotic isochronous to the right of the figure, which is due to the thermos-oxidative acceleration factor which is dependent on the difference of the two aging temperatures. In this synergistic effect, there is always a predominant degradation process which will predict the behavior of the insulation material with the dependence of the condition as shown in Fig. 5.

Since due to time restraints the accelerated aging tests are carried out for the qualification and life-to-service prediction in the shortest time, the use of large acceleration factors (temperature and dose rates) may not render reliable results. In addition, care must be taken during setting the temperature conditions, such that the set temperature may not bring changes in the material which might not occur during normal circumstances. The guidelines for the temperature and radiation range along with the test margins are given by the International Atomic Energy Agency (IAEA) [22].

During the accelerated aging tests, the thermal and radiation combined stress could be either simultaneous or sequential. In sequential, the sequence of stress could be the first temperature and then radiation (thermal-radiation) or reverse sequence (radiation-thermal). The order of the sequence of the stress affects the aging of the insulation which varies with the materials which have been studied by many researchers and has been discussed in the next section. In the sequential stress, one of the stress at the first stage perpetrate more damage which leads to higher damage by the other stress. According to IAEA guidelines, the combination of stress which produces most severe conditions must be adopted and has recommended the simultaneous aging as the preferred test sequence during accelerated aging tests, as it gives more severe conditions, until and unless due to some technical reason the sequential aging can be adopted [22].

\section{Aging markers and uncertainties during condition monitoring}

Conducting life tests for insulation materials of cables under normal operating conditions needs long testing time, so the most effective means is to carry accelerated aging tests at higher temperature and irradiation dose rates. The reliability of life estimation depends on the acceleration methods and the degradation analysis which should be closely related to the degradation mechanism. After the aging of the samples, condition monitoring (CM) techniques, have to be performed to evaluate the condition of the insulation material. The data acquired, aging markers, by the CM techniques, provide a strong basis on the adequate performance of the insulation which helps in managing effectively the aging and degradation in the cables before they reach the end of life. These CM techniques are focused on the measurements of electrical, mechanical properties, thermal analysis, and physiochemical properties, which are classified into destructive and non-destructive tests. To assess the degradation of the insulation material or predict the remaining useful life, a combination of tests is required as the single CM technique is not sufficient. The IAEA in its study has listed the desirable features of the CM techniques [20], while the CM techniques used in recent times are discussed in [30-33]. After the accelerated tests and $\mathrm{CM}$ of the cable, the prediction of the cable condition at the operating conditions is utmost important. This is carried out by the extrapolation of the results. In the last two decades four basic methods of predicting radiation aging behavior of cable materials have been developed; power-law extrapolation method, superposition of time-dependent data, superposition of dose to equivalent data and kinetic model [26].

During the CM analysis of the cable, researchers have found the relationship between the mechanical and electrical properties and a number of uncertainties, some are mention in the IAEA report [22]. These uncertainties need to be considered as they are important for the better understanding of the aging behavior of the insulation material and also for the validation of the tests. The relationship between a number of uncertainties; combination of stress aging, presence of oxygen and antioxidant and inverse temperature, and the mechanical and electrical properties have been put into a framework by studying the effect of them on the mechanical and electrical properties separately for different polymeric insulation materials during the accelerated aging tests conducted by recent authors in their work. 


\subsection{Mechanical properties}

The key mechanical aging markers are elongation at break (EaB), ultimate tensile strength (TS), Young's Modulus $(E)$, etc. which are measured through destructive tests. Out of these properties, EaB is considered as the most reliable aging indicator with a threshold value of $50 \%$ absolute. The function of a cable has no direct influence under the mechanical properties but they indicate the cable ability to withstand vibration and some movement during normal operation and postulated accidents [30]. As discussed earlier cross-linking and chain scission, are responsible for the physiochemical changes of the polymeric material which results in the mechanical properties' degradation, which is dependent on the way the stresses are applied, the presence of oxygen and antioxidants as has been reported by the researchers and are discussed below.

\subsubsection{Effect of simultaneous and sequential stress aging} The effect of simultaneous and sequential stress aging on the mechanical properties (EaB, TS, $100 \%$ modulus, $50 \%$ modulus and hardness) of the different insulation materials have been studied by different researchers [7-10, 29, 34] and are listed in Table 2. The EaB of all the materials decreases under both types of combined stresses. In the sequential stress, the Radiation-Thermal $(R-T)$ has a more pronounced effect on the degradation of $\mathrm{EaB}$ as compared to the Thermal-Radiation $(T-R)$ combination, this is because at first, the radiation stress produces the free radicals which are enhanced by the then temperature stress, which also results in strong thermal oxidation. The TS of all the materials decrease, but EPDM shows different behavior, as the TS first increases then decrease, which is due to the promotion of cross-linking at first stage which is converted to chain scission as the temperature is increased, which is known as a cross over [9]. The $100 \%$ Modulus, Hardness and $50 \%$ Modulus increase for SiR and EPR under all types of combination of stresses, while Young's Modulus (E) decreased for Polypropylene (PP). The effect of the simultaneous stress as compared to the sequential stresses are shown in Fig. 6 for SiR [8].

\subsubsection{Effect of oxygen and antioxidants}

For many of the polymers used in the cables under the thermal-radiation stress, the presence of oxygen (oxidation reaction) adds to the degradation of the insulation material along with the chain scission. The oxidation in the insulation material is the dominant aging mechanism which is initiated both thermally and by irradiation. This mechanism can result in the degradation of the mechanical and electrical properties of the insulation material and may lead to the embrittlement, decrease of EaB; increasing the probability of cracking of the insulation under mechanical stresses

Table 2 Effect of simultaneous and sequential stress on the mechanical properties

\begin{tabular}{|c|c|c|c|c|c|c|c|}
\hline \multirow{2}{*}{ Material } & \multirow{2}{*}{ Type of Stress } & \multicolumn{6}{|c|}{ Mechanical Properties } \\
\hline & & Elongation at Break (EaB) & Tensile Strength & $100 \%$ Modulus & $50 \%$ Modulus & Hardness & $\mathrm{E}$ \\
\hline \multirow{3}{*}{ XLPE [7] } & Simultaneous & $\downarrow^{3}$ & $\downarrow$ & - & - & - & - \\
\hline & $T-R^{1}$ & $\downarrow$ & - & - & - & - & - \\
\hline & $R-T^{2}$ & $\downarrow \downarrow^{4}$ & - & - & - & - & - \\
\hline \multirow{3}{*}{$\operatorname{EPR}[7,10]$} & Simultaneous & $\downarrow$ & $\downarrow \uparrow^{6}$ & - & $\uparrow^{5}$ & - & - \\
\hline & $T-R$ & $\downarrow$ & $\downarrow \uparrow$ & - & $\uparrow$ & - & - \\
\hline & $R-T$ & $\downarrow \downarrow$ & $\downarrow \uparrow$ & - & $\uparrow$ & - & - \\
\hline \multirow{3}{*}{ EPDM [9] } & Simultaneous & $\downarrow$ & $\uparrow \downarrow^{7}$ & - & - & - & - \\
\hline & $T-R$ & - & - & - & - & - & - \\
\hline & $R-T$ & - & - & - & - & - & - \\
\hline \multirow{3}{*}{$\mathrm{SiR}[8]$} & Simultaneous & $\downarrow$ & $\downarrow \downarrow$ & $\uparrow$ & - & $\uparrow$ & - \\
\hline & $T-R$ & $\downarrow$ & $\downarrow$ & $\uparrow$ & - & $\uparrow$ & - \\
\hline & $R-T$ & $\downarrow \downarrow$ & $\downarrow$ & $\uparrow$ & - & $\uparrow$ & - \\
\hline \multirow{3}{*}{ PP [34] } & Simultaneous & $\downarrow$ & $\downarrow$ & - & - & - & $\downarrow$ \\
\hline & $T-R$ & - & - & - & - & - & - \\
\hline & $R-T$ & - & - & - & - & - & - \\
\hline \multicolumn{8}{|c|}{$\begin{array}{l}{ }^{1} T-R: \text { Temperature and then Radiation Sequential Stress } \\
{ }^{2} R-T: \text { Radiation and then Temperature Sequential Stress }\end{array}$} \\
\hline \multicolumn{3}{|c|}{${ }^{3} \downarrow \quad:$ Decrease } & \multirow{2}{*}{\multicolumn{2}{|c|}{$\begin{array}{l}{ }^{4} \downarrow \downarrow: \text { Decrease with more effect } \\
{ }^{7} \uparrow \downarrow: \text { First increase then decrease }\end{array}$}} & \multirow{2}{*}{\multicolumn{3}{|c|}{${ }^{5} \uparrow:$ Increase }} \\
\hline${ }^{6} \downarrow \uparrow:$ First $d$ & ease then increase & & & & & & \\
\hline
\end{tabular}




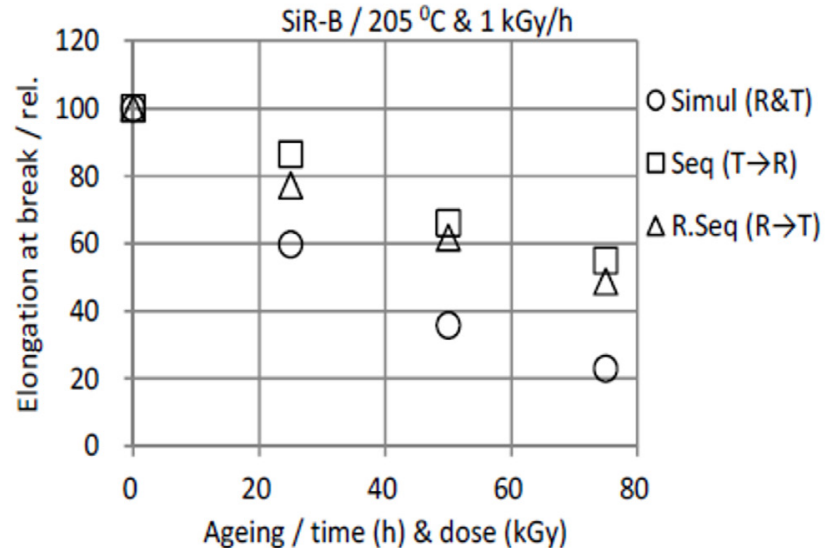

(a)

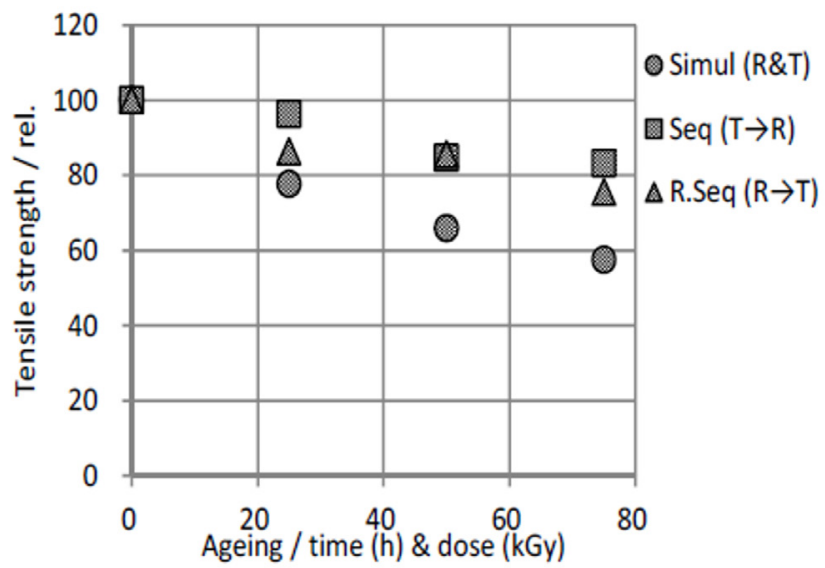

(b)

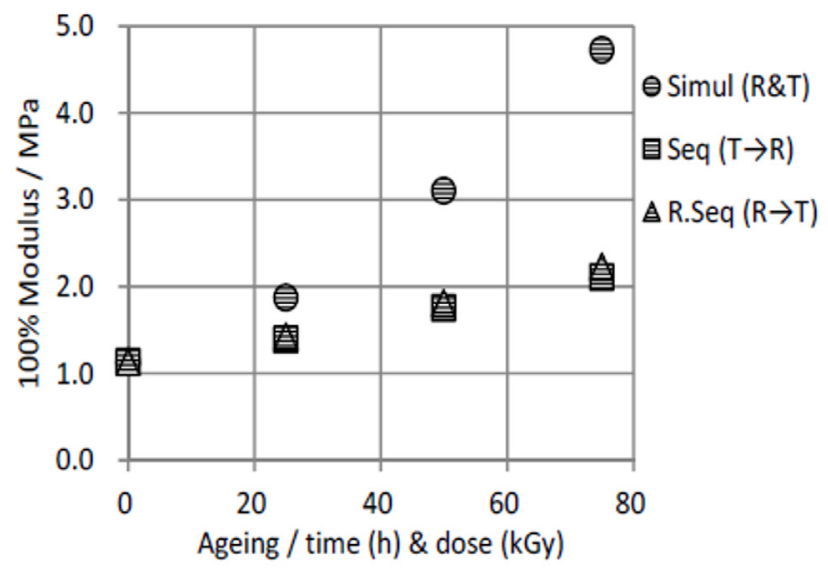

(c)

Fig. 6 Simultaneous and sequential stress effect on (a) Elongation at break, (b) Tensile strength and (c) $100 \%$ Modulus for SiR [8]

and result in the loss of electrical integrity. The diffusion rate of oxygen, average oxidation degree, and thermal-oxidative stability are some of the terms used to relate the effect of oxidation and mechanical properties of insulation materials.

The diffusion rate depends on the structure of the material, so different materials show different degradation

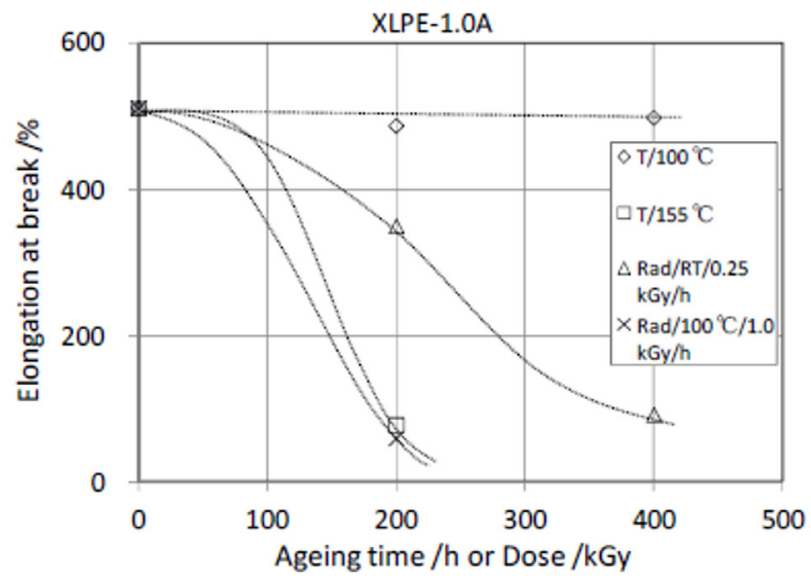

(a)

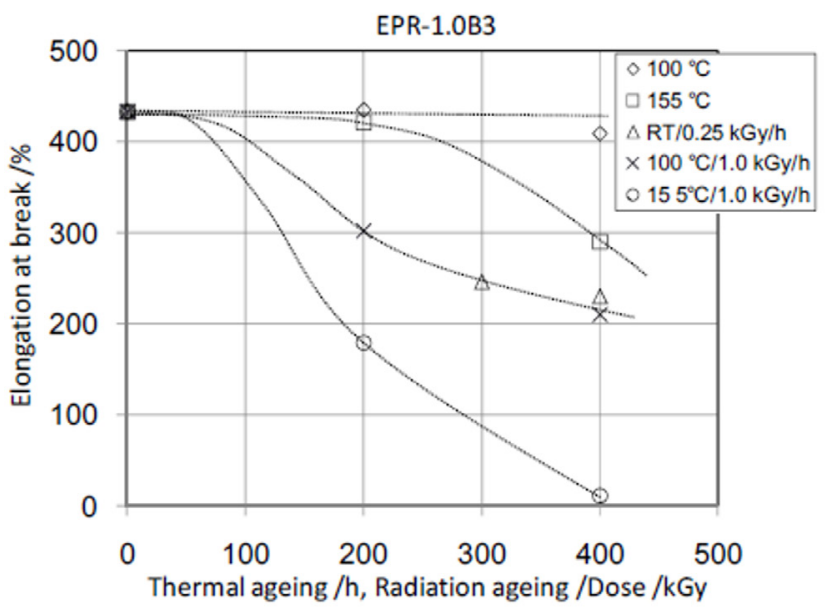

(b)

Fig. 7 Elongation at break of (a) XLPE and (b) EPR due to presence of oxygen [7]

characteristics because of having their own diffusion rate. The phenomenon has been studied in [7] by comparing the mechanical properties of XLPE and EPR. The EPR material showed higher values of the EaB than the XLPE at the same dose due to its high oxygen diffusion rate and low oxygen consumption, Fig. 7 [7]. The EaB with respect to thermo-oxidative stability for PVC has been studied in [11], showing the EaB of PVC decreased due to the decrease in the thermo-oxidative stability. The average oxidation degree has been used to study the effect of oxidation on EaB for XLPE. The EaB decreased as the average oxidation increased at each dose rate, because of the increase of the molecular scission at each dose rate [35].

Another important factor which affects the $\mathrm{EaB}$ and TS of the insulation material in cables is heterogeneous oxidation. This phenomenon occurs during the oxidation when the surface of the material is more exposed to the oxygen as compared to the section of the insulation near to the conductor $[7,29]$, as a consequence more 
degradation is observed at the surface, affecting the mechanical properties of the material.

In the environment having no oxygen or vacuum, with the aging time the $\mathrm{EaB}$ and $100 \%$ modulus change little for the insulation material as compared to degradation in oxygen environment but the degradation in the TS is significant [8], reported for the SiR. Initially, the cross-links are destructed, resulting in a low density of the cross-linking. But as the aging time increased new cross-links are formed due to pyrolysis of the SiR molecules, which increases the crosslink density. It is important to know the type of chemical reaction taking place inside the insulation material during oxidation for the analysis of the degradation of mechanical properties as they show different behavior at a different type of reaction. Such as the degradation in $\mathrm{SiR}$ is due to cross-linking by oxidation while for XLPE and EPR, degradation is via chain scission following oxidation [8].

The type and concentration of antioxidant in the polymer affect the mechanical properties of the insulation material. Since the antioxidant inhibits the acceleration of oxidation rather than stopping it, so the insulation material containing the higher content of the antioxidant was protected from the thermal oxidation up to a higher dose of radiation [36] as shown for XLPE samples with a different density of antioxidants. Those antioxidants having higher molecular weight have a lower evaporation rate as compared to the antioxidant having a lower molecular weight, which makes them good inhibitor to oxidation and hence degradation. It has been reported that for the XLPE, the reduction in the values of the TS and $\mathrm{EaB}$ was more for the sample containing less antioxidant than the one having more.

\subsubsection{Inverse thermal effect}

At low temperatures, due to radiation aging, radicals are generated evenly throughout the insulation material (crystalline and amorphous region). In the crystalline region these radicals are trapped and are unable to react to oxygen because of low chain mobility and low oxygen diffusion rate as compared to the amorphous region where the radicals have high chain mobility and diffusion rate and as a result degradation is proceeded in the amorphous region which affects the mechanical properties of the insulation [37]. The degradation of polyethylene-based insulation materials, XLPE and XLPO due to reverse temperature effect is more prominent as compared to other polymeric insulation materials due to semi-crystalline nature.

\subsection{Electrical properties}

To have the knowledge of the state of the cable under the thermal-radiation multi-stress aging, the investigation of electrical aging markers such as dielectric loss, permittivity, and susceptibility, are carried out by non-destructive test methods. The electrical properties are the most important functional properties, however, research results regarding the effect of the aging on electrical properties of LV cable insulation are still not sufficient to provide effective diagnostic tools, especially for the online testing. Till now, a few techniques have been investigated for LV cables such as Line Resonance Analysis (LIRA), Time Domain Reflectometer (TDR), Voltage Return, dielectric spectroscopy and loss factor [12-15, 38]. The techniques have been adopted to study the dissipation factor $(\tan \delta)$, polarization, permittivity and susceptibility of the material [16, 39-44]. The effect of the uncertainties during the thermal-radiation accelerated aging tests on the electrical properties have also been reported and are discussed here.

\subsubsection{Effect of simultaneous and sequential stress aging} As the order of application of thermal and radiation stress affects the mechanical properties of the insulation materials, the electrical properties are also affected due to the order but the literature reported is very limited. If the radiation stress is applied prior to thermal stress, free radicals are produced. Then due to the application of the thermal stress, the process of chain scission is initiated, as a result, high values of the $\tan \delta$ are reported as compared to the thermal-radiation stress, Fig. 8 [40]. The production of free radicals due to the radiation stress lowers

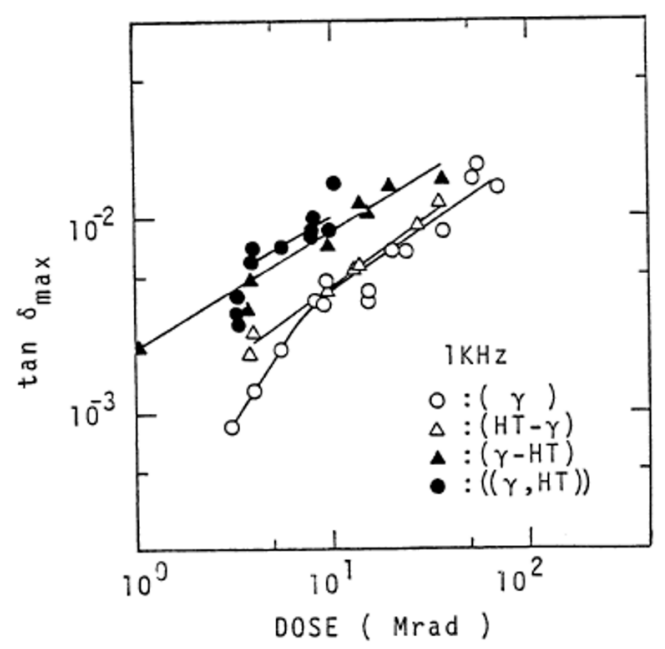

Fig. 8 Effect of order of stress on the $\tan \delta$ with the variation of dose [40] 
the temperature at which the maximum of $\tan \delta$ appears in radiation-thermal stress as compared to the thermal-radiation stress [40]. With the application of the simultaneous stress effect, the DC breakdown strength decreases for PP, which has been reported due to the increase of the degree of crystallinity of the polymer [34].

\subsubsection{Effect of oxygen and antioxidants}

The presence of oxygen during the thermal-radiation stress affects the electrical properties of the insulation material as it does for the mechanical properties. Since the insulation material are polar in nature, so as the material is irradiated, free radicals are formed and the chemical reactions are initiated. It is considered that the chain scission and oxidation reactions result in the formation of the small molecules or polar groups, as a result of which the dipole orientation can be encouraged and the permittivity is enhanced. While crosslinking reaction forms a three-dimensional network within the molecules hence the dipole orientation is restricted, which leads to the decrease of permittivity. Similar behavior has been found for the $\tan \delta$. During the chain scission or oxidation reaction, small molecules or unsaturated bands are formed, which help in the transportation of the charge (ionic or electronic), therefore the conductivity increases. While during the cross-linking, the transportation of charge is limited and hence, the conductivity decreases. So, the structural change in the amorphous region affects the permittivity of the material while the variation of the crystal region affects the conductivity [45-49].

As discussed, due to the formation of the polar groups, the polar orientation will have a great contribution to

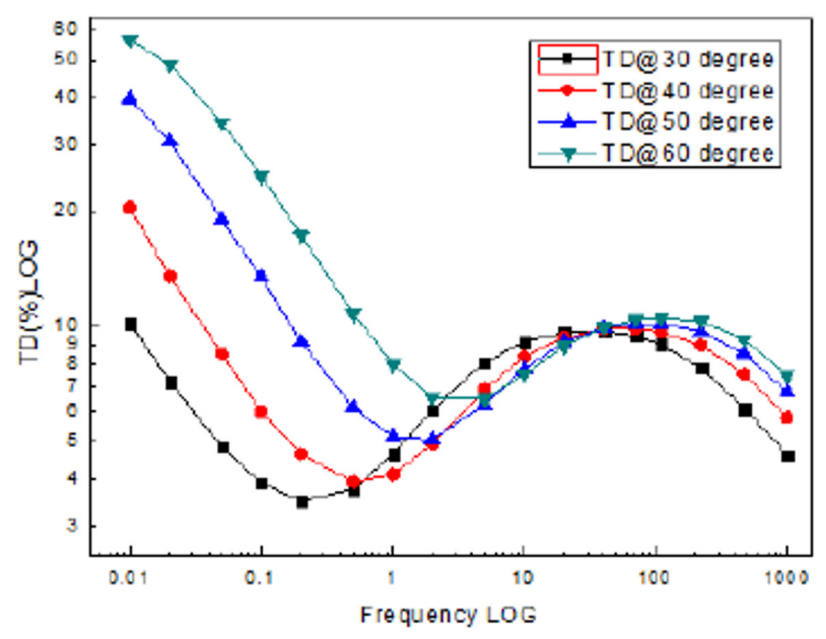

Fig. 9 Behavior of $\tan \delta$ due to frequency variation with different stress conditions [42] the permittivity of the material and hence $\tan \delta$. Since both of them are frequency dependent so their behavior is studied for a wide range of frequency. At a particular radiation dose and thermal aging, with the increase of frequency the $\tan \delta$ decreases and after a certain frequency it starts increasing, Fig. 9 [16, 41, 42]. This behavior of $\tan \delta$ with respect to frequency has been associated due to its dependence on the depolarization, temperature and the antioxidants [42]. As the temperature increases, depolarization time is increased due to the rotation orientation capacity which increases with the temperature as a result $\tan \delta$ attains peak values at low frequency. The peak value of $\tan \delta$ shifts to a higher frequency as the depolarization time increases with the temperature [42].

The real part of the permittivity $\left(\varepsilon^{\prime}\right)$ increases with the decrease of frequency and decreases with the increase of frequency, Fig. 10 (a) [15] for the different types of cable insulation radiated under temperature and radiation

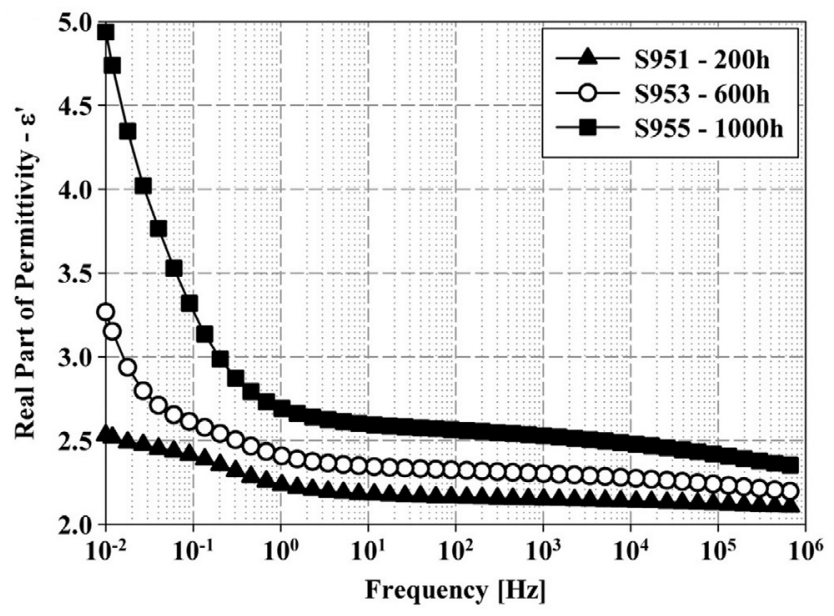

(a)

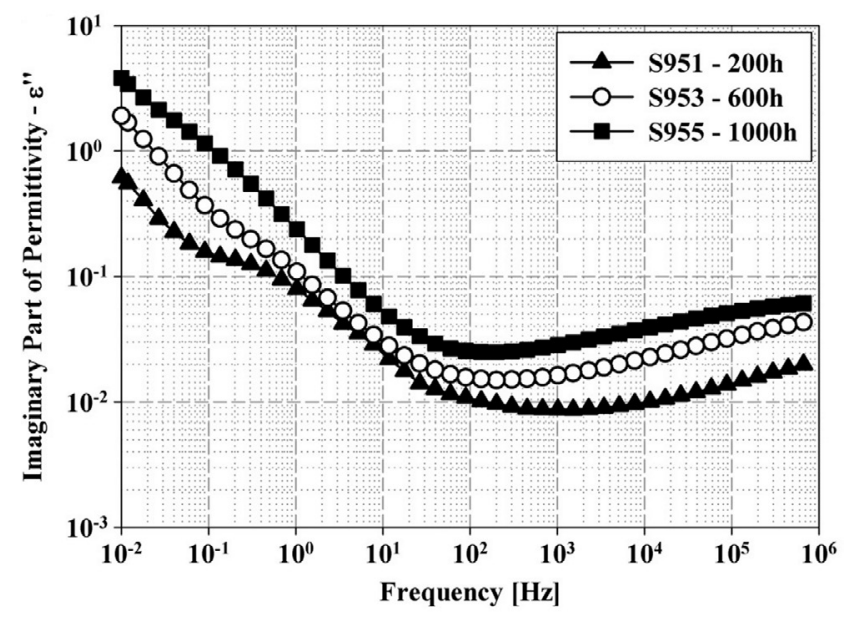

(b)

Fig. 10 (a) Real and (b) Imaginary Part of Permittivity ( $\left.\varepsilon^{\prime}\right)$ v/s Frequency at different stress conditions [15] 
simultaneously due to the dipole orientation inside the material which is dependent on the frequency [15, 16, 43].

The imaginary part of the permittivity $\left(\varepsilon^{\prime \prime}\right)$ decreases with the increase of frequency but it shows more dependency particularly at low frequency, Fig. 10 (b) [15]. This is due to the strong impact of the combined stress on the polymer matrix which results in the enhancement of the interfacial contribution of polarization occurring at low frequencies [43, 44]. The real and imaginary part of susceptibility ( $\Delta \chi^{\prime}$ and $\left.\chi^{\prime \prime}\right)$ increase with the decrease of frequency. The behavior has been associated with the interfacial polarization phenomenon as morphological changes occur during aging, as shown in Fig. 11 [43].

\subsubsection{Inverse thermal effect}

The inverse thermal effect on the $\varepsilon^{\prime \prime}$ has been observed by the authors in $[15,50]$. The experiments conducted on the specimen of EVA cable under the thermal-radiation

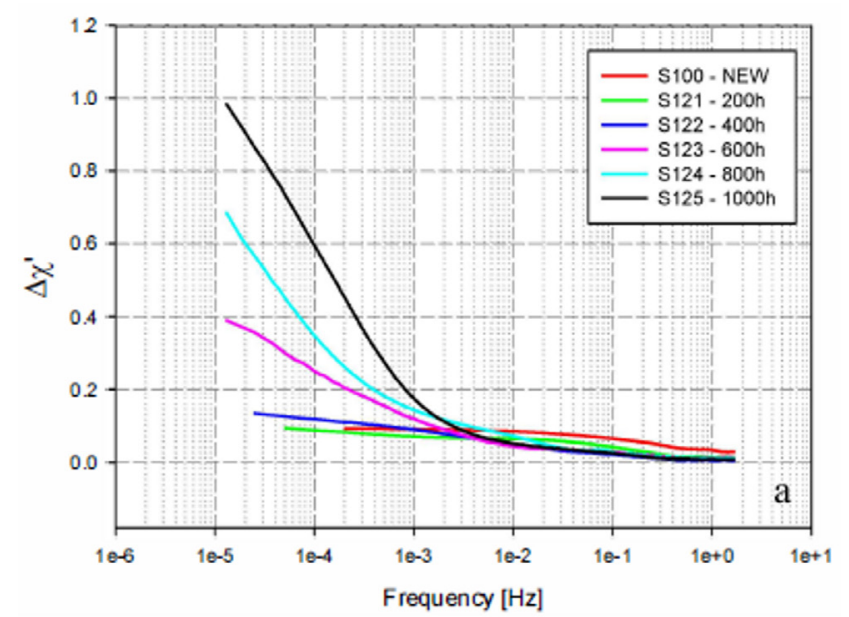

(a)

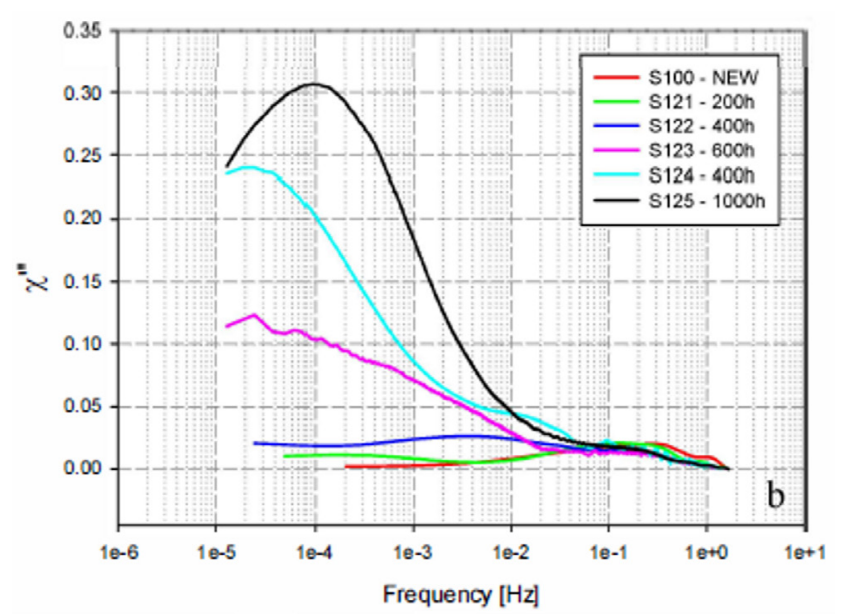

(b)

Fig. 11 (a) Real and (b) Imaginary Part of Susceptibility v/s Frequency at different stress conditions [43] effects, where the imaginary part of permittivity decreases more at low-temperature stress than at higher due to the phenomenon which is associated with the heating of the semi-crystalline polymer in the range of melting endotherm during the radiation treatment. Such aging procedure promotes the radiation-induced crosslinking limiting polymer degradation and hindering oxidation determined by the oxidative induction temperature measurements [50].

\subsection{Correlation between the properties}

As the discussed uncertainties affect the CM of insulation, so to better understand the aging process in the insulation materials correlation between the electrical, mechanical and physiochemical properties of the materials must be studied. A correlation between the electrical property, $\varepsilon^{\prime \prime}$ with the physiochemical property, density is shown in the Fig. 12 [48]. A direct relationship has been observed between them as both are dependent on oxygen diffusion. Since the mechanical property, EaB is being considered as the main aging marker for the insulation material. Increase in the value of $\mathrm{EaB}$ is correlated by the decrease of " $\varepsilon$ " [48], which shows the correlation among the properties.

\section{Conclusion and possible future directions}

Keeping in view the importance of the CM in the light of NPP LV cables, a review of thermal and radiation multistress on the aging of cables used in NPP has been carried in this work. Stating the real reason for the degradation of the insulation material in LV cables varies with each manufacturer and type of insulation material which makes the aging of the insulation as a complex system [51]. So, to state the actual reason for the degradation of the insulation material until now is a challengeable task.

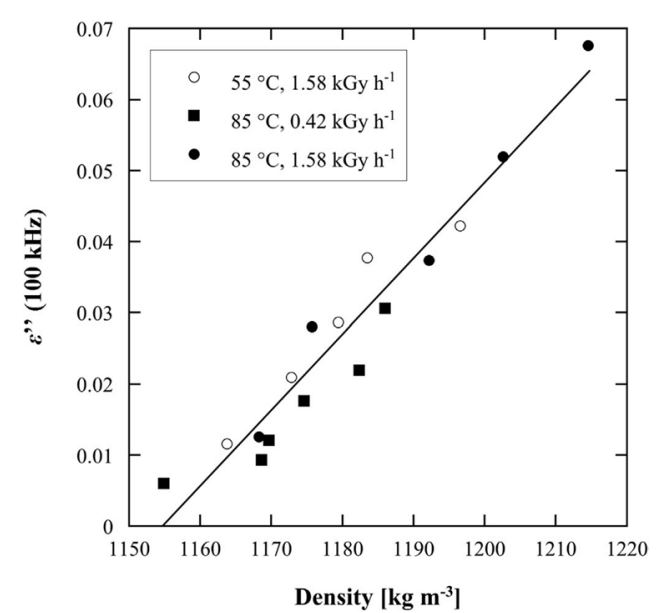

Fig. 12 Correlation between Imaginary Part of Permittivity $\left(\varepsilon^{\prime \prime}\right)$ and Density [48] 
Based on the discussions and literature review, following steps towards a better understanding of thermal-radiation multi-stress aging in LV cables used in NPP are suggested:

1. Since there is a number of non-destructive testing procedures, which involve different electrical tests but still there is no universal testing procedure. Also, there is no single technique that covers all the requirements, hence the potentially new methods and a combination of different (chemical, mechanical and electrical) test methods can be used to better understand the degradation of insulating materials because of thermal-radiation multi-stress.

2. Due to the chemical reactions, there is a formation of the polar groups which affect the permittivity and may result in the number of polarization processes, slow and fast polarization process. These processes need to be investigated with the help of electrical tests, which will help in the better understanding of the thermal-radiation multi-stress aging.

\section{References}

[1] De Reggi, A. S., van Roggen, A., Serjeant, W. J. "Aging Models, Mechanisms and Reality", IEEE Transactions on Electrical Insulation, 28(5), pp. 713-714, 1993.

[2] Aagarwal, V. K., Banford, H. M., Bernstein, B. S., Brancato, E. L., Fouracre, R. A., Montanari, G. C., Parpal, J. L., Seguin, J. N., Ryder, D. M., Tanaka, J. "The Mysteris of Multifactor Ageing", IEEE Electrical Insulation Magazine, 11(3), pp. 37-43, 1995. https://doi.org/10.1109/57.387831

[3] International Electrotechnical Commission "IEC 60610 Principal Aspects of Functional Evaluation of Electrical Insulation Systems: Aging Mechanisms and Diagnostic Procedures", International Electrotechnical Commission (IEC), Geneva, Switzerland, 1978.

[4] International Electrotechnical Commission "IEC 60792-1 MultiFactor Functional Testing of Electrical Insulation Systems. Part 1: Test Procedures", International Electrotechnical Commission (IEC), Geneva, Switzerland, 1985.

[5] Banford, H. M., Fouracre, R. A. "Nuclear Technology and Ageing", IEEE Electrical Insulation Magazine, 15(5), pp. 19-27, 1999. https:/doi.org/10.1109/57.793826

[6] Gazdzinski, R. F., Denny, W. M., Toman, G. J., Butwin, R. T. "Aging Management Guideline for Commercial Nuclear Power Plants Electrical Cable and Terminations", Sandia National Laboratories, Albuquerque, New Mexico, USA, Rep. SAND96-0344, 1996.

[7] Shimada, A., Sugimoto, M., Kudoh, H., Tamura, K., Seguchi, T. "Radiation Ageing Technique for Cable Life Evaluation of Nuclear Power Plant", IEEE Transactions on Dielectrics and Electrical Insulation, 19(5), pp. 1768-1773, 2012. https://doi.org/10.1109/TDEI.2012.6311526

[8] Shimada, A., Sugimoto, M., Kudoh, H., Tamura, K., Seguchi, T. "Degradation Mechanisms of Silicone Rubber (SiR) by Accelerated Ageing for Cables of Nuclear Power Plant", IEEE Transactions on Dielectrics and Electrical Insulation, 21(1), pp. 16-23, 2014. https://doi.org/10.1109/TDEI.2013.004177
3. The effect of aging on the frequency dependence of the $\tan \delta$ and complex permittivity of the insulation materials although has been studied by the authors, but the relationship of this phenomenon to the changing of the material structure by aging still requires in-depth. As a number of polarization processes are happening inside the material especially at very low frequency, $\mathrm{mHz}$ and $\mu \mathrm{Hz}$ level, so the study of these frequency dependent processes need more attention.

4. In this very low-frequency range, the investigation of electrical properties such as conductivity and dielectric polarization due to thermal-radiation stress aging could open new ways of developing non-destructive examination methods for LV NPP cables.

\section{Acknowledgment}

This work has been supported by the National Research, Development and Innovation Fund of Hungary, finance under the KNN_16 funding scheme vide Project no. 123672.

[9] Ŝrac, T., Quiévy, N., Gusarov, A., Konstantinović, M. J. "The study of temperature and radiation induced degradation of cable polymers: A comparison between the mechanical properties of industrial and neat EPDM", Procedia Structural Integrity, 2, pp. 2405-2414, 2016. https://doi.org/10.1016/j.prostr.2016.06.301

[10] Seguchi, T., Tamura, K., Kudoh, H., Shimada, A., Sugimoto, M. "Degradation of Cable Insulation Material by Accelerated Thermal Radiation Combined Ageing", IEEE Transactions on Dielectrics and Electrical Insulations, 22(6), pp. 3197-3206, 2015. https://doi.org/10.1109/TDEI.2015.004880

[11] Santhosh, T. V., Ghosh, A. K., Fernandes, B. G., Dubey, K. A. "Performance assessment of I\&C cable insulation materials by DSC and SEM for NPP ageing management", International Journal of System Assurance Engineering and Management, 7(1), pp. 6-15, 2016. https://doi.org/10.1007/s13198-015-0387-x

[12] Ekelund, M., Fantoni, P. F., Gedde, U. W. "Thermal ageing assessment of EPDM-chlorosulfonated polyethylene insulated cables using line resonance analysis (LIRA)", Polymer Testing, 30(1), pp. 86-93, 2011.

https://doi.org/10.1016/j.polymertesting.2010.11.003

[13] Banford, H. M., Fouracre, R. A., MacGregor, S. J., Judd, M. "An Investigation of Radiation-Induced Ageing in Cable Insulation via Loss Measurements at High and Low Frequencies", In: IEEE International Symposium on Electrical Insulation, Arlington, Virginia, USA, 1998, pp. 558-561. https://doi.org/10.1109/ELINSL.1998.694854

[14] Braun, J. M. "Condition Assessment of Unshielded Aged Power and Control Cables by Electrical Techniques", IEEE Electrical Insulation Magazine, 8(5), pp. 27-33, 1992. https://doi.org/10.1109/57.156942 
[15] Verardi, L., Fabiani, D., Montanari, G. C. "Electrical aging markers for EPR-based low-voltage cable insulation wiring of nuclear power plants", Radiation Physics and Chemistry, 94, pp. 166-170, 2014. https://doi.org/10.1016/j.radphyschem.2013.05.038

[16] Lee, C., Lee, K.-B. "Radiation effects on dielectric properties of ethylene propylene rubber", Journal of Industrial and Engineering Chemistry, 14(4), pp. 473-479, 2008. https://doi.org/10.1016/j.jiec.2008.01.018

[17] Laghari, J. R. "Multifactor Stress Aging of Electrical Insulation", Air Force Office of Scientific, Research, Wahington, DC, USA, Rep. AD-A-232915/9/XAB (CNN: AFOSR-89-0272), 1990.

[18] IEEE, Radiation Effects Committee of the IEEE Dielectrics and Electrical Insulation Society "IEEE Std 775-1993 Guide for Designing Multistress Aging Tests of Electrical Insulation in a Radiation Environment", Institute of Electrical and Electronics Engineers (IEEE), New York, USA, 1993. https://doi.org/10.1109/IEEESTD.1993.119220

[19] IEEE, Nuclear Power Engineering Committee of the IEEE Power Engineering Society "IEEE Std 1205-2000 (Reaffirmed: 2007) Guide for Assessing, Monitoring, and Mitigating Aging Effects on Class 1E Equipment Used in Nuclear Power Generating Stations", Institute of Electrical and Electronics Engineers (IEEE), New York, USA, 2007. https://doi.org/10.1109/IEEESTD.2000.92294

[20] IAEA "Pilot Study on the Management of Ageing of Instrumentation and Control Cables", International Atomic Energy Agency (IAEA), Vienna, Austria, Rep. IAEA-TECDOC-932, 1997.

[21] Kröhnke, C. "8.14 - Polymer Additives", In: Matyjaszewski, K., Möller, M. (eds.) Polymer Science: A Comprehensive Reference, 1st ed., Elsevier Science, Amsterdam, The Netherlands, 2012, pp. 349-375.

https://doi.org/10.1016/B978-0-444-53349-4.00212-0

[22] IAEA "Assessing and Managing Cable Ageing in Nuclear Power Plants", International Atomic Energy Agency (IAEA), Vienna, Austria, Rep. IAEA Nuclear Energy Series No. NP-T-3.6, 2012.

[23] IAEA "Stability and stabilization of polymers under irradiation", International Atomic Energy Agency (IAEA), Vienna, Austria, Rep. IAEA-TECDOC-1062, 1999.

[24] Seguchi, T., Tamura, K., Ohshima, T., Shimada, A., Kudoh, H. "Degradation mechanisms of cable insulation materials during radiation-thermal ageing in radiation environment", Radiation Physics and Chemistry, 80(2), pp. 268-273, 2011.

https://doi.org/10.1016/j.radphyschem.2010.07.045

[25] Verardi, L. "Aging of nuclear power plant cables: in search of non-destructive diagnostic quantities", PhD Thesis, University of Bologna, Bologna, Italy, 2013.

https:/doi.org/10.6092/unibo/amsdottorato/6246

[26] Gillen, K. T., Clough, R. L., Jones, L. H. "Investigation of Cable Deterioration in the Containment Building of the Savannah River Nuclear Reactor", U.S. Nuclear Regulatory Comission, Washington, D.C., USA, Rep. NUREG/CR-2877 (SAND81-2613, ON: DE83000817), 1982. https:/doi.org/10.2172/7094253

[27] Gillen, K. T., Clough, R. L. "Predictive Aging Results for Cable Materials in Nuclear Power Plants", U.S. Department of Energy, Washington, D.C., USA, Rep. SAND-90-2009 (ON: DE91006428, TRN: 91-004382), 1990.

https://doi.org/10.2172/6189683
[28] Bartoniček, B., Hnát, V., Plaček, V. "Radiation Ageing of Polymers", Czechoslovak Journal of Physics, 49(Supplement 1), pp. 485-491, 1999.

https://doi.org/10.1007/s10582-999-0065-9

[29] Behera, A. K., Beck, C. E., Alsammarae, A. "Cable Aging Phenomena under Accelerated Aging Conditions", IEEE Transactions on Nuclear Science, 43(3), pp. 1889-1893, 1996.

https://doi.org/10.1109/23.507241

[30] IAEA "Benchmark Analysis for Condition Monitoring Test Techniques of Aged Low Voltage Cables in Nuclear Power Plants", International Atomic Energy Agency (IAEA), Vienna, Austria, Rep. IAEA-TECDOC-1825, 2017.

[31] Subudhi, M. "Literature Review of Environmental Qualification of Safety-Related Electric Cables", U.S. Nuclear Regulatory Commission, Washington, DC, USA, Rep. NUREG/CR-6384Vol. 1 (BNL-NUREG-52480-Vol. 1, ON: TI96009367, TRN: AHC29610\%\%70), vol. 1, 1996. https://doi.org/10.2172/226028

[32] Toman, G. "Initial Acceptance Criteria Concepts and Data for Assessing Longevity of Low-Voltage Cable Insulations and Jackets", Electric Power Research Institute (EPRI), Palo Alto, California, USA, Rep. 1008211, 2005.

[33] Villaran, M., Lofaro, R. "Condition Monitoring of Cables Task 3 Report: Condition Monitoring Techniques for Electric Cables", U.S. Nuclear Regulatory Commission, Washington, DC, USA, Rep. BNL-90735-2009-IR (R\&D Project: N-6744, 401001060, TRN: US1102639), 2009. https://doi.org/10.2172/1013436

[34] Cygan, S. P., Laghari, J. R. "Effects of Multistress Aging (Radiation, Thermal, Electrical) on Polypropylene", IEEE Transactions on Nuclear Science, 38(3), pp. 906-912, 1991. https://doi.org/10.1109/23.81692

[35] Kurihara, T., Takahashi, T., Homma, H., Okamoto, T. "Oxidation of Cross-linked Polyethylene due to Radiation-thermal Deterioration", IEEE Transactions on Dielectrics and Electrical Insulations, 18(3), pp. 878-887, 2011. https://doi.org/10.1109/TDEI.2011.5931077

[36] Shimada, A., Sugimoto, M., Kudoh, H., Tamura, K., Seguchi, T. "Degradation Distribution in Insulation Materials of Cables by Accelerated Thermal and Radiation Ageing", IEEE Transactions on Dielectrics and Electrical Insulations, 20(6), pp. 2107-2116, 2013. https://doi.org/10.1109/TDEI.2013.6678859

[37] Burnay, S. G., Dawson, J. "Reverse Temperature Effect during Radiation Ageing of XLPE Cable Insulation", In: Mallinson, L. G. (ed.) Ageing Studies and Lifetime Extension of Materials, Springer, Boston, MA, USA, 2001, pp. 493-497. https://doi.org/10.1007/978-1-4615-1215-8_54

[38] Tamus, Z. A., Berta, I. "Application of Voltage Response Measurement on Low Voltage Cables", In: IEEE Electrical Insulation Conference, Montreal, QC, Canada, 2009, pp. 444-447. https://doi.org/10.1109/EIC.2009.5166387

[39] Mustafa, E., Afia, R. S. A., Adam, T. Z. "A Review of Methods and Associated Models used in Return Voltage Measurement", In: International Conference on Diagnostics in Electrical Engineering, Pilsen, Czech Republic, 2018, pp. 1-4. https://doi.org/10.1109/DIAGNOSTIKA.2018.8526127 
[40] Nakamura, S., Murabayashi, F., Iida, K., Sawa, G., Ieda, M. "Degradation of Dielectric Properties of Polyethylene by Combined $\gamma$-Irradiation and Thermal Stresses", IEEE Transactions on Electrical Insulation, EI-22(6), pp. 715-720, 1987. https://doi.org/10.1109/TEI.1987.298932

[41] Verardi, L., Fabiani, D., Montanari, G. C., Žák, P. "Electrical condition monitoring techniques for low-voltage cables used in nuclear power plants", In: IEEE Electrical Insulation Conference, Ottawa, Ontario, Canada, 2013, pp. 504-508. https://doi.org/10.1109/EIC.2013.6554299

[42] Yizhou, Z., Lei, W., Pengyu, Z., Liang, W., Xuan, G., Ge, T., Huiming, M. "Ageing Inspection for Cross-Linked Polyolefin Insulation Cable in NPP Using Dielectric Property", In: $25^{\text {th }}$ International Conference on Nuclear Engineering, Shanghai, China, 2017, paper number: V001T01A021. https://doi.org/10.1115/ICONE25-66673

[43] Verardi, L., Fabiani, D., Montanari, G. C., Placek, V. "Electrical Aging Markers for Low-Voltage Cable Insulation Wiring of Nuclear Power Plants", In: IEEE $10^{\text {th }}$ International Conference on the Properties and Applications of Dielectric Materials, Bangalore, India, 2012, pp. 1-4. https://doi.org/10.1109/ICPADM.2012.6318966

[44] Linde, E., Verardi, L., Fabiani, D., Gedde, U. W. "Dielectric spectroscopy as a condition monitoring technique for cable insulation based on crosslinked polyethylene", Polymer Testing, 44, pp. 135-142, 2015. https://doi.org/10.1016/j.polymertesting.2015.04.004

[45] Gao, Y., Du, B. X. "Effect of Gamma-ray Irradiation on Permittivity and Dielectric Loss of Polymer Insulating Materials", In: International Conference on High Voltage Engineering and Application, Shanghai, China, 2012, pp. 229-232. https://doi.org/10.1109/ICHVE.2012.6357027
[46] Suljovrujić, E., Kostoski, D., Dojčilović, J. "Charge trapping in gamma irradiated low-density polyethylene", Polymer Degradation and Stability, 74(1), pp. 167-170, 2001. https://doi.org/10.1016/S0141-3910(01)00150-1

[47] Kostoski, D., Dojčilović, J., Novaković, L., Suljovrujić, E. "Effects of charge trapping in gamma irradiated and accelerated aged low-density polyethylene", Polymer Degradation and Stability, 91(9), pp. 2229-2232, 2006. https://doi.org/10.1016/j.polymdegradstab.2005.12.016

[48] Linde, E., Verardi, L., Pourmand, P., Fabiani, D., Gedde, U. W. "Non-destructive condition monitoring of aged ethylene-propylene copolymer cable insulation samples using dielectric spectroscopy and NMR spectroscopy", Polymer Testing, 46, pp. 72-78, 2015.

https://doi.org/10.1016/j.polymertesting.2015.07.002

[49] Verardi, L., Fabiani, D., Montanari, G. C. "Correlation of electrical and mechanical properties in accelerated aging of LV nuclear power plant cables", In: International Conference on High Voltage Engineering and Application, Poznan, Poland, 2014, pp. 1-4. https://doi.org/10.1109/ICHVE.2014.7035376

[50] Przybytniak, G., Boguski, J., Placek, V., Verardi, L., Fabiani, D., Linde, E., Gedde, U. W. "Inverse effect in simultaneous thermal and radiation aging of EVA insulation", eXPRESS Polymer Letters, 9(4), pp. 384-393, 2015. https://doi.org/10.3144/expresspolymlett.2015.36

[51] Orosz, T., Tamus, Z. A. "Impact of the Cooling Equipment on the Key Design Parameters of a Core-Form Power Transformer", Journal of Electrical Engineering, 67(6), pp. 399-406, 2016. https://doi.org/10.1515/jee-2016-0058 